\title{
c\&d-LEARNING IMPLEMENTATION ARCHITECTURE Adapting e-Learning to Developing Countries
}

\author{
Jesus Martinez-Mateo, Susana Munoz-Hernandez and David Perez-Rey \\ Facultad de Informática, Universidad Politécnica de Madrid, Spain
}

Keywords: Educational methods, e-Learning, Thin clients, Cooperation for the development, Satellite connection, Internet access, Teleconference, Videoconference, Off-line courses.

\begin{abstract}
From the educational point of view, the most widespread method in developing countries is on-site education. Technical and economic resources cannot support conventional distance learning infrastructures and it is even worse for courses in universities. They usually suffer a lack of qualified faculty staff, especially in technical degrees. The literature suggest that e-learning is a suitable solution for this problem, but its methods are developed attending to educational necessities of the First World and cannot be applied directly to other contexts. The proposed methodology is a variant of traditional e-learning adapted to the needs of developing countries. E-learning for Cooperation and Development (c\&d-learning) is oriented to be used for educational institutions without adequate technical or human resources. In this paper we describe the $c \& d-l e a r n i n g ~ i m p l e m e n t a t i o n$ architecture based on three main phases: hardware, communication and software; e.g. computer and technical equipping, internet accessing and e-learning platform adaptation. Proper adaptation of educational contents to c\&d-learning is discussed and a real case of application in which the authors are involved is described: the Ngozi University at Burundi.
\end{abstract}

\section{INTRODUCTION}

Modern research in cooperation for development is led toward innovative solutions for (institutions and people's) problems at developing countries. Traditional technical problems at educational institutions in these countries have been identified. There are many proposals to use e-learning tools at developing countries, but in general they are only affordable for the most advanced universities in the Third World. A crucial goal of cooperation is to improve education at developing countries. Research on learning, and specifically on e-learning, is one of the most productive research fields at occidental universities. Nevertheless, advances in these areas are made regarding educational needs of developed countries, where the situation is quite different from developing countries. Those differences are not only technical, but also at the human and communication level.

Universities of developed countries have a number of agreements with universities of developing countries, but these collaborations are with the most important universities of those countries. In general, cooperation is oriented to improve the teaching or develop research. It is difficult to find relationships of occidental universities with poor and small developing countries universities to help with their main deficiencies. Many e-learning collaborations arrangements are established between universities of the North and the South, but they are based on north elearning tools and conventional requirements. In general, they are not suitable for small universities with low resources from developing countries.

The cooperation group TEDECO ${ }^{1}$ has been studying the necessities of a group of universities of Central Africa (Ngozi, Mwaro and Bujumbura universities at Burundi; and Bukavu University, Peace University, High Pedagogy Institute at Congo Democratic Republic). Some common problems have been identified such as damaged wires, irregular electric supply, outdated hardware, lack of internet connection, lack of specific software, lack of technical faculty staff and, of course, economic problems. In addition, the situation is completely different to occidental universities. In conventional e-learning the professor is

\footnotetext{
${ }^{1}$ Technology for the Development and the Cooperation, http://tedeco.fi.upm.es/
} 
working full time at the university and the students have Internet connection at their houses. They may study in an asynchronous timetable using e-learning platforms. At our target universities the situation is completely different. As the students do not have computers at home they need to go to the university facilities to get Internet access. Regarding the lack of teaching staff, students may attend to the university following a fixed schedule without professor guidance.

Attending to these differences it is quite obvious that conventional e-learning cannot be applied to developing countries universities. An adaptation of hardware and communication conditions is needed to use e-learning applications in a different way. Contents should be also adapted thinking about the specific context of the classes. This paper aims to cover the majority of these tasks.

During the last two years, TEDECO has been working with the University of Ngozi at Burundi ${ }^{2}$ thanks to Technical University of Madrid funding (TESON, 2006; TICAMEN, 2008). We illustrate this proposal with some explanations related to our expertise implementing the architecture that we propose at the University of Ngozi.

\section{ICT IN DEVELOPING COUNTRIES}

In first world countries Information and Communication Technologies (ICT) are applied to the majority of daily life fields, in professional and scientific environments but also in social and cultural ones (figure 1). They are powerful tools, essential for modern development. However, specific necessities in developing countries produce that ICT are applied in a different way or with slightly different objectives (Blogs ICT, 2008). Although there exist other application scopes of ICT in developing countries, the main areas are health (e-health) and education (e-learning).

In a first approach, it may seem that these countries have other priorities related to "survival" before education. But from a long term perspective, the development enhanced by education produce these basic improvements. Any development concept is each day more relate to ICTs (Oswalder, 2003). Therefore it is necessary to apply sustainable actions to improve Internet and telecommunication accesses and to improve knowledge about information technologies in general, so the development of local Web content (UNCTAD, 2004). In fact, these infrastruc-

\footnotetext{
${ }^{2}$ http://www.ung.bi/
}

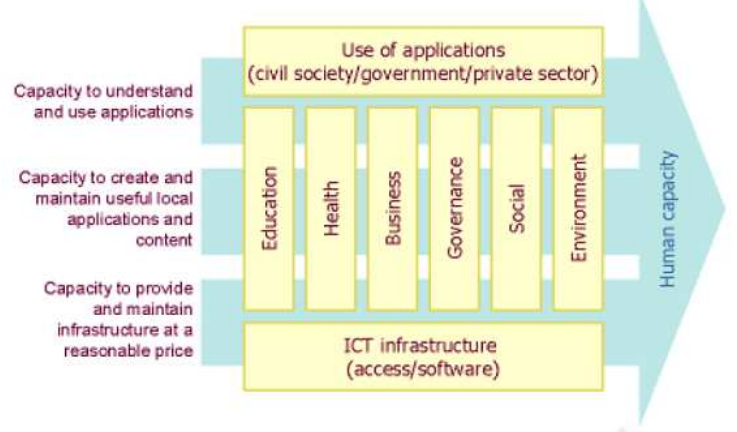

Figure 1: ICT cross-impact (Oswalder, 2003).

tures are growing at a faster rate than expected in developing countries. In some cases such as Internet access through mobile technologies, these countries are adopting cutting-edge technologies that developed countries do not implement yet, since traditional ones are still widely extended (UNCTAD, 2004).

E-learning may be defined in its widest meaning as: "electronic or based in technology learning". This e-learning interpretation may lead to several applications, but nowadays, e-learning and TICs are generally used as tools for (Ardizzone and Rivoltella, 2004):

- make a more visible and modern University,

- as an extension of the learning offer,

- or as a learning virtualization.

Our proposal aims to take learning beyond a global market, heading towards the idea of a universal learning. The e-learning can be the tool that allows the multiplicity of professors, transporting their effort also to developing countries. Within the application of ICT in developing countries, e-learning is specially interesting, since it permit to overcome the physical limitations of traditional learning, promoting education as the main remedy for poverty. These countries lack of resources and infrastructures to implement appropriate learning methodologies, therefore, technologies that permit distance education are very important. There exist a special lack of human resources with skills in science and technologies, which together with an increment of students make e-learning suitable to be implemented in developing countries. Finally, as an added incentive, e-learning facilitates the technological transference from first world countries to developing countries.

An appropriate technological and economic infrastructure is required to exploit e-learning correctly. This infrastructure must cover three resources listed below (Kamel, 2006):

- Financing. In most cases, developing countries 
governments have a limited budget for education, where usually, not every student has access to a free university education.

- Infrastructure. Closely related to financing problems is the lack of infrastructures: public works, teaching staff and communications among others.

- Content. It is essential to provide a teaching staff that evaluate the student learning and include adapted content to e-learning platforms.

As a result, to implement an e-learning application in developing countries a coordinated effort in these three requirements is needed. Many countries do not have a proper communication network, especially outside big cities. And where the communication network does exist, there is not financing resources to pay the connection. And when these two conditions are satisfied, there is usually a lack of educational contents. To solve the former problem, elearning may profit from open course programs such as the MIT Open Course Ware (MIT, 2008). However, this content cannot be included directly, but after an adaptation to each situation. Although some basic subjects are universal, others include social and cultural aspects, or they must be adjusted to the educative level of these universities.

The e-learning is being disseminated more and more in developing countries through different project, such as:

- Programa de Actualización de Maestros en Educación, AME, funded by Fundación Cisneros in Latin America (Fundación Cisneros, 2008),

- the Global Learning Opportunities On the Web, GLOW (Challenge, 2008),

- and the African Virtual University, AVU (Wolff, 2002).

The former organization, AVU, use ICT to offer sub-saharan countries access to some academic resources over the World. The final goal is to alleviate the technological gap due to the lack of scientific, engineers, technicians, and other professionals that would facilitate the economic and social development of Africa through the information society.

In a real case where the authors are involved, a traditional distance educational method has been adapted to special necessities and limitations encountered during development at University of Ngozi. Due to innovative elements of the proposed method we refer to it as cooperation and development -learning (c\&d-learning) (Escudero et al., 2008).

\section{C\&D-LEARNING IMPLEMENTATION ARCHITECTURE}

We propose a three-phase architecture that should be implemented starting by the bottom one. We explain details about each phase in the rest of this section. Figure 2 provides a detailed representation of the implementation architecture (in particular, the one that is being introduced at the University of Ngozi).

TEDECO group has already finished the implementation of the first and second phase at the University of Ngozi during the execution of the TESON project (TESON, 2006). Nowadays the third phase is progressing thanks to funding through the TICAMEN project (TICAMEN, 2008). We illustrate each of following sub-section using our experience in these two projects.

\subsection{Hardware Phase}

Due to technical problems that target universities use to suffer, the implementation of the c\&d-learning is extremely important to ensure that the hardware infrastructure would work properly. This process has been divided into three sub-phases listed below:

- electric current stabilization,

- installation of several computer classrooms for teaching (e-learning),

- installation of a local network (intranet) to connect computers within the university.

The hardware phase was finished with technical equipment adaptation and training of human resources. These resources were needed for a local network that should be built and maintained by qualified local staff.

\subsubsection{Electric Supply}

Frequent shutdowns and lack of power stability, are two facts that pose the following question: are developing countries ready for solutions designed at developed ones? The answer is probably no, but we may adapt these solutions and solve some of these problems developing alternative technologies. For example, one of the most promising solutions to palliate the electric supply problems is using solar energy.

Solar panels are a good alternative to common power supply in those regions where shutdowns are frequent. However we found a new limitation: the complete shutdown - the number of systems able to operate with a solar power supply is very small. However, solar panels may also be used to stabilize the 


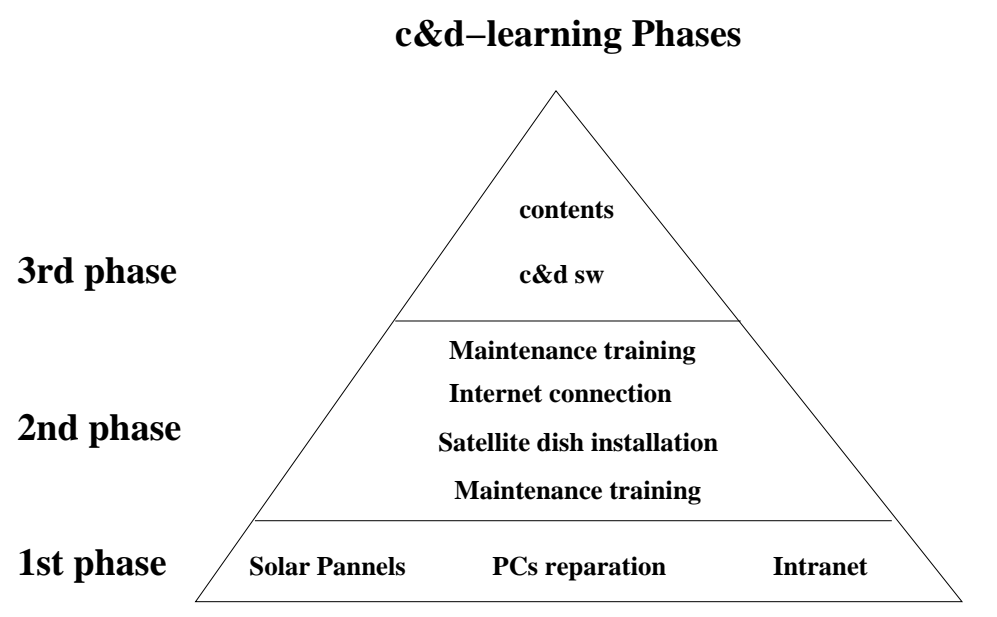

Sw

\section{Communication}

Hw

Figure 2: Detailed c\&d-learning Implementation Phases.

power supply. The stabilization of the electric current is essential when the entire educational model depends on a technological infrastructure.

The main drawbacks when using technologies in development are the major constraints that appear implementing a solution that should be stable over time.

\subsubsection{Computer Classrooms and Maintenance}

A sustainable solution must be based on the use of available resources, so before purchasing new computers and other hardware, the analysis of the current state of the equipment at the University of Ngozi was carried out (Osin, 1998). The second major limitation of these countries arose then: outdated hardwaresolution: thin client technology.

These two limitations, problems with the electric supply and outdated hardware, forced us to design a different strategy to rebuild the new computer-based classrooms. Following a thin client approach, outdated computers may be reused as terminals. This solution also allows a fast recovery of user computers after a power outage (Martínez et al., 2008). Actually this was our first work, computer reparation, selecting the most powerful computers to be used as servers in a thin client-based network. The sacrifice of a high performance computer - which in a developed country would be used as a simple $\mathrm{PC}^{3}$ - allows reuse a number of old computers. The number of terminals connected to a single server (i.e. number of old computers reused per available server) will depend on the performance of it. The installation of a thin clientbased solution requires the development of a special software for the resource sharing between client and server (Martínez and Pérez, 2008). Communication is

\footnotetext{
${ }^{3}$ Personal Computer.
}

accomplished by sending the desktop from the server to the client, which entails a mandatory network consumption, which will depend on the content displayed by the client.

\subsubsection{Intranet}

The main purpose of a local network is to enable a shared access to Internet for employees and students at UNG. For general Internet access, the maximum bandwidth required by the local network is not a critical parameter (as will be shown later). The bandwidth provided by a local network is in any case far greater than the bandwidth available for Internet. Current networking technologies use gigabit connections, although 100 or $10 \mathrm{Mbps}$ can be found yet. However, the implemented network is indeed a bottleneck due thin client technologies (exposed above) that require significant use of network traffic.

\subsection{Communication Phase}

Developing countries generally do not have a large deployment of conventional infrastructures for telecommunications, traditionally implemented by telephone networks. Non-standard connection technologies must be used to overcome connection problem in these countries. For this project with the University of Ngozi we have installed and tested a satellite connection.

\subsubsection{Satellite Connection}

The use of satellite communication implies some limitations that are important not only from a technical point of view, but also from an academic perspective regarding educational content preparation. The 
most important characteristic of a satellite connection is the asynchronous communication, i.e. the information is sent and received through independent channels (downstream and upstream). The bandwidth of the upstream channel (or return channel) is quite lower than the bandwidth of the downstream channel. In addition, the return channel is limited by other and more important- effect: the latency ${ }^{4}$.

All these problems are predictable and known in advance, but there is an additional problem that cannot be always controlled: the performance of a satellite connection depends on external factors. Unsettled conditions may imply certain instability in the satellite connection-i.e. weather. The number of satellite connections in a region also affects these connections; in general, the total bandwidth of a territory is shared by all the connected users.

\subsubsection{Connection Sustainability}

It is crucial to guarantee the sustainability of the every infrastructure deployed in these developments. Otherwise the whole project will fail. The lack of sustainability in solutions adopted is one of the main causes of useless cooperation efforts. We included training for the local team to maintain PCs and intranet infrastructures. At this point a similar training process is necessary for the communication infrastructure.

However, the sustainability related to satellite connections includes an economic component. Satellite connection should be paid and the local institution (University) should make sure this payment. In the University of Ngozi case we encouraged the installation of a cyber within the campus to collect the satellite connection fee. A viability plan was prepared at the beginning of the implementation of the project to guarantee its sustainability.

\subsection{Software Phase}

Although some software applications have been already developed in two previous phases, a third and final phase is being carried out which works exclusively adapting and developing a learning platform.

\subsubsection{Learning Platform}

With several open and available learning platform, every day is more difficult to justify the development of this software from scratch. Free solutions such as

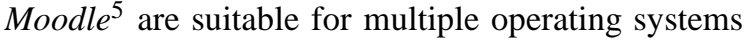
and are backed by a large community-i.e. forums,

\footnotetext{
${ }^{4}$ Delay to transmit any information.

${ }^{5}$ http://moodle.org/
}

documentation, updates, etc. Consequently, these solutions can be adapted to every user requirements.

In our case we are currently working to adapt Moodle to developing countries requirements, optimizing an asynchronous education model with three new features:

- an automatic content synchronization avoiding the use of the Internet connection in periods with high demand of bandwidth (working hours);

- an enhanced off-line courses management system,

- and a new role, the local professor as a content facilitator to local students.

A learning platform adaptation is needed. First world countries demand other characteristics from these software tools and after review the state of the art, there are none that cover all these issues.

\subsubsection{Support Software and Digital Ink}

More and more applications are available on the market in relation to e-learning support software. Frequently, these tools are referred to as digital ink when they are used in a live environment, e.g. Classroom Presenter $^{6}$ (Anderson et al., 2007). The value of these applications seems fairly interesting for e-learning, but our experience - mainly in the communication channel- shows us that this software is still far from its application in developing countries.

\section{CONTENTS ADAPTATION}

Two main possibilities may be considered to present educational content to a group of students:

- using a single device visible by all the students (e.g. by using a projector) is the first approach to transmit educational contents,

- distributing the content to every student using a computer-based classroom.

Communication systems based on conferences cover the first option. The second one requires considering resources available at the institution. This paper describe a situation that face the former option together with thin client limitations.

\subsection{Conference}

Direct communication may be essential for some educational activities such as tutoring. Videoconference is certainly the best solution to transmit information

\footnotetext{
${ }^{6} \mathrm{http}: / /$ classroompresenter.cs.washington.edu/
} 
over long distances, but its requirements do not allow the use of this technology in several circumstances. Reduced bandwidth, a connection frequently interrupted or delayed because of network traffic are some issues that may prevent using videoconferences for teaching when scenarios with a minimum quality are required to transmit information properly.

The satellite communication cause the main limitation considered in our situation, i.e. asynchronous connection, high latency in the return channel, and shared bandwidth. Therefore, we are compelled to explore all possible alternatives for communication, such as teleconference or videoconference described below.

\subsubsection{Teleconference}

The minimum technology required for an on-line communication is teleconference, i.e. a communication where only audio is transmitted. Even for this simple communication, problems caused by an asynchronous connection and the delay of the return channels due to latency must be considered. However, it is not mandatory that the audio channel is synchronized, and can be transmitted following just one direction (the downstream direction). The return channel can be text-based, e.g. chat. The teleconference can be easily enhanced using a mixed system where audio is complemented with images updated by the speaker: slides, or a webcam picture of the professor among others.

\subsubsection{Videoconference}

Videoconferences only requires a higher bandwidth, so it is also affected by the same problems in communication: synchronization, latency, etc. For example, in a satellite communication the videoconference should be also transmitted in one direction. In fact, videoconferences are similar to enhanced teleconferences where images are updated in higher frequencies.

Using this strategy a priority management must be carried out ensuring audio rather than video, so the communication should be divided into two distinct channels. A reduction of bandwidth will cause a reduction of video quality, but not audio, essential to understand the communication content.

Nowadays, Google Inc. ${ }^{7}$ offer a free solution with these two possibilities, teleconference and videoconference, with an acceptable quality, Google Talk. It is particularly interesting with asyncrhonous communications between sender and receiver, providing possi-

\footnotetext{
${ }^{7}$ http://www.google.com/
}

bilities of sending audio and video only in one direction, using a written reply for the other direction.

\subsubsection{Off-line Courses}

When there is no guarantee in sending audio or video, it is strongly recommended the use of an alternative, such as the off-line exposure of a subject. This option is specially interesting in those partnerships where there is a significant time difference, such as in cooperation between universities in Europe and Latin America.

\subsection{Content Presentation}

Educational content adaptation has meet some technological limitations. For example, a solution based on thin client technology has remarkable limitations inherent to its structure, mainly focused on network usage. This should be also taken into account when different options for e-learning are considered. For example, the graphic below (figure 3) shows two curves with the bandwidth consumed by thin clients in different scenarios:

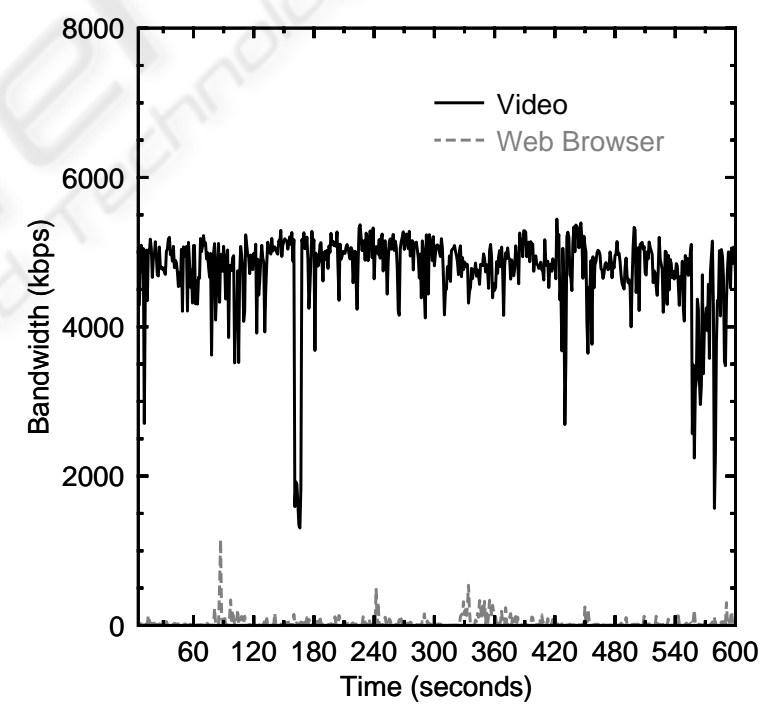

Figure 3: Bandwidth consumption in a thin client-based network.

- In the first scenario, the terminal is playing a video. The bandwidth consumed is shown by a continuous line, which appears at the top of the figure.

- In the other scenario, the terminal is visiting web sites through a web browser. The consumption is shown with a dotted line, which can be observed at the bottom of the figure. 
The difference is quite significant suggesting that video, and multimedia content in general, should not be included within the information transmitted to every student. Since we have assembled computer classrooms with low-performance equipment, and the internal network does not allow the transport of a high bandwidth, there are some limitations that suggest some rules to create educational content, such as:

- remove multimedia contents (video, animations, etc.) to avoid permanent desktop updates consuming the bandwidth,

- slide resolution reduction, i.e. less content by slide and more slides.

In summary, any bandwidth reduction is an improvement in these situations. Specially those related with unnecessary visual effects.

\section{CONCLUSIONS}

During many years the survival of universities with our means at the south depends on the charity of foreign professors that travel to these countries to teach. Depending on help received it may be an unsustainable solution, so it is not acceptable.

A number of universities at developing countries are in a difficult situation for economic problems. Elearning could be widely used at these universities to overcome some economic issues. Nevertheless, the minority of centers that use e-learning in south countries are the most advanced ones. It is a paradox, but classical e-learning is not adapted to these countries due to specific needs and technical characteristics. Elearning is oriented to facilitate things to occidental students with technological possibilities but it is not oriented to help students without means.

We have proposed (Escudero et al., 2008) a variant of e-learning adapted to developing countries limitations. In this paper we provide an architecture to implement the so-called c\&d-learning. It is a complete proposal that cover from hardware details to software adaptation issues or communication infrastructures. The most important characteristic of these implementation should be always the sustainability.

Our architecture is backed by our experience at the University of Ngozi. Where the two first phases have been completed within TESON project (TESON, 2006) obtaining promising results, and we are currently working in the third phase in the framework of the TICAMEN project (TICAMEN, 2008).

\section{ACKNOWLEDGEMENTS}

Thanks to the Universidad Politécnica de Madrid (particularly to the Cooperation for the Development direction) for its economic and logistic support, and to the Bishopric of Ngozi and to the University of Ngozi.

\section{REFERENCES}

Anderson, R., Anderson, R., Davis, P., Linnell, N., Prince, C., Razmov, V., and Videon, F. (2007). Classroom presenter: Enhancing interactive education with digital ink. Computer, 40(9):56-61.

Ardizzone, P. and Rivoltella, P. (2004). Didáctica para elearning: Métodos e instrumentos para la innovación de la enseñanza universitaria. Ediciones Aljibe.

Blogs ICT (2008). Blogs about: Ict in developing countries. http://wordpress.com/tag/ict-in-developingcountries/.

Challenge, S. (2008). Glow: Global learning opportunities on the web. http://www.stockholmchallenge.se/.

Escudero, F., Muñoz, S., Pérez-Rey, D., and Suárez, F. (2008). c\&d-learning: b-learning eficiente adaptado a países en desarrollo con bajos recursos. In IV Congreso Universidad y Cooperacion al Desarrollo.

Fundación Cisneros (2008). Programa de actuación de maestros en educación (ame). http://www.ame.cisneros.org/.

Kamel, S. (2006). Electronic business in developing countries, opportunities and challenges. Idea Group Publishing, USA.

Martínez, J. and Pérez, I. (2008). Lan core: Thin client server, operating system and management application. http://lancore.sourceforge.net/.

Martínez, J., Pérez, I., Muñoz, S., and Lancho, D. (2008). Thin clients in the academic environment. In IV Congreso Universidad y Cooperacion al Desarrollo.

MIT (2008). Open course ware. Massachusetts Institute of Technology, http://ocw.mit.edu/.

Osin, L. (1998). Computers in education in developing countries: Why and how? In Education and Technology Series.

Oswalder, A. (2003). Ict in developing countries: A crosssectioral snapshot. In Proceedings ISGLOB'03, IS Perspectives and Challenges in the Context of Globalization.

TESON (2006). Technology for sustainability of the university of ngozi. http://www.upm.es/rinternacional/cooperacion/.

TICAMEN (2008). Comunication and information technologies applied to education enhancement in ngozi. http://www.upm.es/rinternacional/cooperacion/.

UNCTAD (2004). Ict as an enabler for growth, competitiveness and development: Implications for national and international policies and actions. In 
CSEDU 2009 - International Conference on Computer Supported Education

United Nations Conference on Trade and Development. http://www.unctad.org/.

Wolff, L. (2002). The african virtual university: The challenge of higher education development in subsaharan africa. TechKnowLogia, International Journal of Technologies for the Advancement of Knowledge and Learning, 4(2). 